\title{
Benzodithiophene-based low band-gap polymers with deep HOMO levels: synthesis, characterization, and photovoltaic performance
}

\author{
Kazuhiro Nakabayashi, Hiroshi Otani and Hideharu Mori
}

\begin{abstract}
A series of benzo[1,2-b:4,5- $\left.b^{\prime}\right]$ dithiophene-based low band-gap polymers were synthesized using Stille coupling reactions. The polymers with electron-withdrawing side chains (P1, P2, P4 and P5) exhibited wide absorption due to the bathochromic effect derived from the electron-withdrawing side chains compared with P3 and P6, which possessed hexyl side chains. Furthermore, as donor materials, P1, P2, P4 and P5 exhibited deep HOMO levels ( -5.53 to $-5.65 \mathrm{eV})$ due to the incorporation of electron-

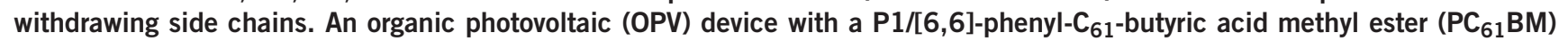
active layer achieved a power conversion efficiency (PCE) of $2.68 \%$ with an open-circuit voltage $\left(V_{o c}\right)$ of $0.71 \mathrm{~V}$, a short-circuit current density $\left(J_{\mathrm{sc}}\right)$ of $10.64 \mathrm{~mA} \mathrm{~cm}^{-2}$ and a fill factor (FF) of 0.35 . By contrast, the OPV device with the P3/PC ${ }_{61} B M$ active layer exhibited a PCE of $0.86 \%$ with a $V_{\mathrm{oc}}$ of $0.59 \mathrm{~V}, J_{\mathrm{sc}}$ of $4.93 \mathrm{~mA} \mathrm{~cm}-2$ and $\mathrm{FF}$ of 0.30 . This comparison demonstrates that the deep HOMO level derived from the incorporation of the electron-withdrawing side chains contributed to the larger $V_{o c}$ and higher PCE values for P1 than those of P3.
\end{abstract}

Polymer Journal (2015) 47, 617-623; doi:10.1038/pj.2015.41; published online 17 June 2015

\section{INTRODUCTION}

Organic photovoltaics (OPVs) based on conjugated polymeric materials have received considerable attention in recent years because of their advantages (for example, low cost, light weight, flexibility, and facile large-scale fabrication) compared with silicon-based solar cells. ${ }^{1-4}$ One of the most successful systems currently utilizes a blend of regioregular poly(3-hexylthiophene) (P3HT) and [6,6]-phenyl- $\mathrm{C}_{61}$-butyric acid methyl ester $\left(\mathrm{PC}_{61} \mathrm{BM}\right)$ as the donor and acceptor materials, respectively, in the active layer, which provide power conversion efficiencies (PCEs) in the range of 3 and $4 \%$. To further improve PCEs, the development of novel donor polymers with enhanced light-harvesting properties (that is, low band-gap polymers) has been extensively explored. For example, the benzo[1,2-b:4,5-b]dithiophene (BDT)-, ,-11 $^{-14}$ cyclopenta[2,1-b:3,4-b] dithiophene-, ${ }^{12,13}$ dithieno[3,2-b:2',3'-d] silole-, ${ }^{14}$ diketopyrrolo[3,4-c]-pyrrole-1,4-dione-, ${ }^{15}$ and thieno[3,4-c]pyrrole4,6-dione ${ }^{16}$-based polymers have shown good promise with lower band gaps $\left(E_{\mathrm{g}} \mathrm{opt}\right)$ than that of P3HT $\left(E_{\mathrm{g}}^{\mathrm{opt}}=1.90 \mathrm{eV}\right)$. To date, OPVs using these low band-gap polymers have achieved excellent PCEs due to a high short-circuit current density $\left(J_{\mathrm{Sc}}\right)$. In particular, a PCE of $>9 \%$ was reported from an OPV with a BDT-based low band-gap polymer. ${ }^{11}$ These results indicate that low band-gap polymers are promising polymer motifs for high performance OPVs.

The major drawback of conventional donor polymers lies in their relatively high HOMO energy levels. The high HOMO levels in donor materials result in a low open-circuit voltage $\left(V_{\text {oc }}\right)$, which is directly related to the HOMO/LUMO offset of the donor and acceptor materials in the OPVs and prevents further improvement of the OPV performance. One method of controlling the HOMO/LUMO levels is the incorporation of electron-withdrawing units into the polymers. Previous studies have indicated that the incorporation of electron-withdrawing units into polymer backbones results in low LUMO levels. For example, donor-acceptor alternate copolymers containing arylene bisimide units are promising acceptor materials due to their low LUMO levels $(c a .-4.0 \mathrm{eV}) .{ }^{17-19}$ However, the incorporation of electron-withdrawing side chains into polymers can be an effective method for achieving low (deep) HOMO levels. Recently, Thompson and co-workers ${ }^{20}$ reported that a random P3HT-co-3-cyanothiophene) copolymer exhibited lower HOMO levels $(5.30-5.34 \mathrm{eV})$ than P3HT $(5.20 \mathrm{eV})$ due to the incorporation of electron-withdrawing cyano side chains, which contributed to a larger $V_{\text {oc }}$ in the random P3HT-co-3-cyanothiophene copolymer/ $\mathrm{PC}_{61} \mathrm{BM}$ system in the range of 0.72 and $0.80 \mathrm{~V}$ (by contrast, the $V_{\text {oc }}$ with $\mathrm{P} 3 \mathrm{HT} / \mathrm{PC}_{61} \mathrm{BM}$ was $0.60 \mathrm{~V}$ ). The $\mathrm{OPV}$ with the random P3HT-co-3-cyanothiophene copolymer achieved a higher PCE (3.29\%) than that with P3HT (2.70\%). This result suggested that the incorporation of electron-withdrawing side chains into polymers can lead to improvement of PCEs derived from the deeper HOMO levels in the donor polymers; however, further development of the polymer is essential for achieving excellent PCEs. 
Herein, we describe BDT-based low band-gap polymers with electron-withdrawing side chains prepared using Stille coupling reactions between bis(trimethyltin)-BDT-based monomers (that is, 2,6-bis(trimethyltin)-4,8-bis(2-ethylhexyloxy)benzo[1,2-b:4,5- $\left.b^{\prime}\right]$ dithiophene (BDT1) and 2,6-bis(trimethyltin)-4,8-bis(2-(ethylhexyloxy)thienyl)benzo[1,2-b:4,5- $\left.b^{\prime}\right]$ dithiophene (BDT2)) and dibromothiophene monomers with electron-withdrawing side chains (that is, 2,5-dibromo-3-(cyanomethyl)thiophene (Th1), and 2,5-dibromo3-cyanothiophene (Th2)). From this polymer design, low-lying HOMO levels derived from the incorporation of electronwithdrawing side chains are expected without sacrificing the excellent light-harvesting properties derived from the BDT-based structure, resulting in higher $V_{\mathrm{oc}}$ values while maintaining light-harvesting properties than those of conventional donor polymers. In this study, a series of novel BDT-based low band-gap polymers with electronwithdrawing side chains (cyano or cyanomethyl group) was successfully synthesized using a combination of the aforementioned monomers in the presence of $\mathrm{Pd}\left(\mathrm{PPh}_{3}\right)_{4}$ under typical Stille coupling reaction conditions. Furthermore, their optical and electrochemical properties, thin film morphology and OPV performances were investigated in detail.

\section{EXPERIMENTAL PROCEDURE}

\section{Materials}

All of the reagents and solvents were used as received unless otherwise stated. BDT1, ${ }^{21,22}$ BDT2, ${ }^{23,24}$ Th1, ${ }^{25,26}$ Th2 $^{27}$ and 2,5-dibromo-3-hexylthiophene $(\mathrm{Th} 3)^{28}$ were synthesized according to previously published protocols.

\section{Procedure for the synthesis of polymers (P1-6)}

A typical procedure for the synthesis of the polymers is as follows (P1): The dry toluene/DMF solution $(10 \mathrm{ml}, 4: 1 \mathrm{v} / \mathrm{v})$ of BDT1 $(190 \mathrm{mg}, 0.3 \mathrm{mmol})$, Th1 $(80 \mathrm{mg}, 0.3 \mathrm{mmol})$, and $\mathrm{Pd}\left(\mathrm{PPh}_{3}\right)_{4}(3 \mathrm{mg}, 8 \mathrm{~mol} \%)$ were refluxed for 2 days under a nitrogen atmosphere. After the reaction, the mixture was poured into methanol $(120 \mathrm{ml})$ to yield the precipitate. The obtained precipitate was purified by Soxhlet extraction with methanol followed by extraction with chloroform (CF). The CF fraction was filtered through Celite, and poured into methanol $(120 \mathrm{ml})$ to yield a red solid $(130 \mathrm{mg}, 91 \%) . M_{\mathrm{n}}=11800$, $M_{\mathrm{w}} / M_{\mathrm{n}}=1.47 .{ }^{1} \mathrm{H}$ NMR $\left(\mathrm{CDCl}_{3}\right.$, $\delta$, p.p.m.): 8.50-6.45 (br, 3H), 4.50-3.35 (br, 6H), 2.35-0.80 (m, 30H).

\section{P2 from BTD1 and Th2}

Red solid (78\%). $M_{\mathrm{n}}=12400, M_{\mathrm{w}} / M_{\mathrm{n}}=1.23 .{ }^{1} \mathrm{H}$ NMR $\left(\mathrm{CDCl}_{3}, \delta\right.$, p.p.m.): 8.60-6.10 (br, 3H), 4.55-3.65 (br, 4H), 2.50-0.80 (m, 30H).

\section{P3 from BTD1 and Th3}

Red solid (89\%). $M_{\mathrm{n}}=10700, M_{\mathrm{w}} / M_{\mathrm{n}}=1.47 .{ }^{1} \mathrm{H} \mathrm{NMR}\left(\mathrm{CDCl}_{3}, \delta\right.$, p.p.m.): 7.60-7.00 (br, 3H), 4.35-4.00 (br, $4 \mathrm{H}), \quad 3.80-3.50$ (m, 2H), 2.25-0.85 (br, $41 \mathrm{H})$.

\section{P4 from BTD2 and Th1}

Red solid (55\%). $M_{\mathrm{n}}=7500, M_{\mathrm{w}} / M_{\mathrm{n}}=1.40 .{ }^{1} \mathrm{H}$ NMR $\left(\mathrm{CDCl}_{3}, \delta\right.$, p.p.m.): 7.90-6.00 (br, 5H), 4.00-2.25 (br, 6H), 2.15-0.80 (m, 30H).

\section{P5 from BTD2 and Th2}

Red solid $(20 \%) . M_{\mathrm{n}}=3200, M_{\mathrm{w}} / M_{\mathrm{n}}=1.21 .{ }^{1} \mathrm{H} \mathrm{NMR}\left(\mathrm{CDCl}_{3}, \delta\right.$, p.p.m.): 7.90-6.50 (br, 5H), 4.00-3.25 (br, 4H), 2.35-0.80 (m, 30H).

\section{P6 from BTD2 and Th3}

Red solid (79\%). $M_{\mathrm{n}}=6900, M_{\mathrm{w}} / M_{\mathrm{n}}=1.70 .{ }^{1} \mathrm{H} \mathrm{NMR}\left(\mathrm{CDCl}_{3}, \delta\right.$, p.p.m.): 7.90-6.50 (br, 5H), 3.75-3.25 (br, 4H), 2.95-2.25 (br, 2H), $1.95-0.80$ (br, 37H).

\section{Device fabrication and measurements}

A typical procedure for the preparation of the indium tin oxide (ITO)/poly $(3,4-$ ethylenedioxythiophene):poly(styrenesulfonate) (PEDOT:PSS)/polymer:PC ${ }_{61} \mathrm{BM} /$ $\mathrm{Ca} / \mathrm{Al}$ architecture is as follows: commercially available prepatterned ITO substrates with a sheet resistance of $15 \Omega / \square$ were cleaned and plasma-etched prior to coating with a 30-nm layer of PEDOT: PSS, spin coated at 4000 r.p.m. for $40 \mathrm{~s}$ followed by annealing under flowing nitrogen at $120^{\circ} \mathrm{C}$ for $10 \mathrm{~min}$. The substrates were allowed to cool under a nitrogen atmosphere and then transferred to a glovebox for active layer deposition. The polymer: $\mathrm{PC}_{61} \mathrm{BM}$ blend solution was spin coated at 700 r.p.m. for 90 s. The blend solution, which consisted of $10 \mathrm{mg}$ of each polymer dissolved in $1 \mathrm{ml}$ of solvent (1:1 by weight, conc. $=20 \mathrm{mg} \mathrm{ml}^{-1}$ ), was prepared in a glovebox. Then, the top electrode that consisted of Ca interlayer $(20 \mathrm{~nm})$ and Al electrode $(80 \mathrm{~nm})$ was applied using vacuum deposition. The density-voltage $(J-V)$ characteristics of the devices were measured using a direct-current voltage and a current source/monitor (BSO-X500L, Bunko-Keiki, Tokyo, Japan) in a nitrogen atmosphere under an AM1.5G simulated solar light at $100 \mathrm{~mW} \mathrm{~cm}^{-2}$. The light intensity was corrected with a calibrated silicon photodiode reference cell (BS-520, Bunko-Keiki).

\section{Characterization}

The ${ }^{1} \mathrm{H}(400 \mathrm{MHz})$ NMR spectra were recorded with a JEOL JNM-ECX400 (JEOL, Tokyo, Japan). The ultraviolet-visible (UV-Vis) spectra were recorded on a JASCO V-630BIO UV-Vis spectrophotometer (JASCO, Tokyo, Japan). The number-average molecular weight $\left(M_{\mathrm{n}}\right)$ and molecular weight distribution $\left(M_{\mathrm{w}} / M_{\mathrm{n}}\right)$ were estimated by size exclusion chromatography using a HLC-8320 system (TOYO Corporation, Tokyo, Japan). The column setup was as follows: a guard column (TSK guard column $\mathrm{H}_{\mathrm{XL}} \mathrm{L}$, (TOYO Corporation)) and three consecutive columns $\left(\mathrm{G} 4000 \mathrm{H}_{\mathrm{XL}}, \mathrm{G} 3000 \mathrm{H}_{\mathrm{XL}}\right.$ and $\left.\mathrm{G} 2000 \mathrm{H}_{\mathrm{XL}}\right)$ were eluted with $\mathrm{CF}$ at a flow rate of $1.0 \mathrm{ml} \mathrm{min}^{-1}$. Polystyrene standards were employed for calibration. Cyclic voltammetry experiments for the polymer thin films were performed on a BAS (Tokyo, Japan) electrochemical analyzer (model 660C). A three-electrode cell was used with platinum electrodes as both the counter and working electrodes. Silver/silver ion ( $\mathrm{Ag}$ in $0.1 \mathrm{M} \mathrm{AgNO}_{3}$ solution) was used as the reference electrode. Ferrocene/ferrocenium $\left(\mathrm{Fc} / \mathrm{Fc}^{+}\right)$was used as an internal standard. The potential values obtained in reference to $\mathrm{Ag} / \mathrm{Ag}^{+}$were converted to the values relative to the saturated calomel electrode. Thermal analysis was performed on a SEIKO SSC6200 and SEIKO EXSTAR 6000 DSC 6200 at a heating rate of $10{ }^{\circ} \mathrm{C} \mathrm{min}^{-1}$ for thermogravimetry and differential scanning calorimetry (DSC) under a nitrogen atmosphere, respectively. Tapping mode atomic force microscopy (AFM) observation was performed with an Agilent (Agilent Technologies, Santa Clara, CA, USA) AFM 5500 using microfabricated cantilevers with a force constant of $\sim 34 \mathrm{~N} \mathrm{~m}^{-1}$.

\section{RESULTS AND DISCUSSION}

\section{Synthesis and Characterization}

The monomers for the synthesis of the polymers (that is, BDT1, BDT2, Th1, Th2 and Th3) were prepared according to previously reported protocols. ${ }^{18-25}$ Then, Stille coupling reactions were carried out in the presence of $\mathrm{Pd}\left(\mathrm{PPh}_{3}\right)_{4}$ for 2 days in a toluene/DMF solution under refluxing conditions (Scheme 1). ${ }^{29}$ The results are summarized in Table 1. P1 was obtained as a red solid in high yield (91\%) with a molecular weight that was estimated to be $M_{\mathrm{n}}=11800$ and $M_{\mathrm{w}} / M_{\mathrm{n}}=1.47$ based on size exclusion chromatography analysis. P2 and P3 were successfully obtained in relatively high yields (78 and $89 \%)$, and their molecular weights were $M_{\mathrm{n}}=12400\left(M_{\mathrm{w}} / M_{\mathrm{n}}=1.23\right)$ and $M_{\mathrm{n}}=10700\left(M_{\mathrm{w}} / M_{\mathrm{n}}=1.47\right)$, respectively, based on size exclusion chromatography analysis. The molecular weight of P3, which was previously reported $\left(M_{\mathrm{n}}=10800\right.$, and $\left.M_{\mathrm{w}} / M_{\mathrm{n}}=1.7\right)$, was nearly the same value as that of $\mathbf{P 3}$ synthesized here. ${ }^{29} \mathbf{P 4}, \mathbf{P 5}$ and $\mathbf{P 6}$ were also synthesized under Stille coupling reaction conditions. However, large amounts of the CF-insoluble fractions were formed in P4 and P5. The molecular weights of the CF-soluble P4 and P5 fractions were estimated to be $M_{n}=7500$ and $M_{n}=3200$, respectively. In addition, the yield of each was relatively low (55\% and $20 \%$, respectively). 

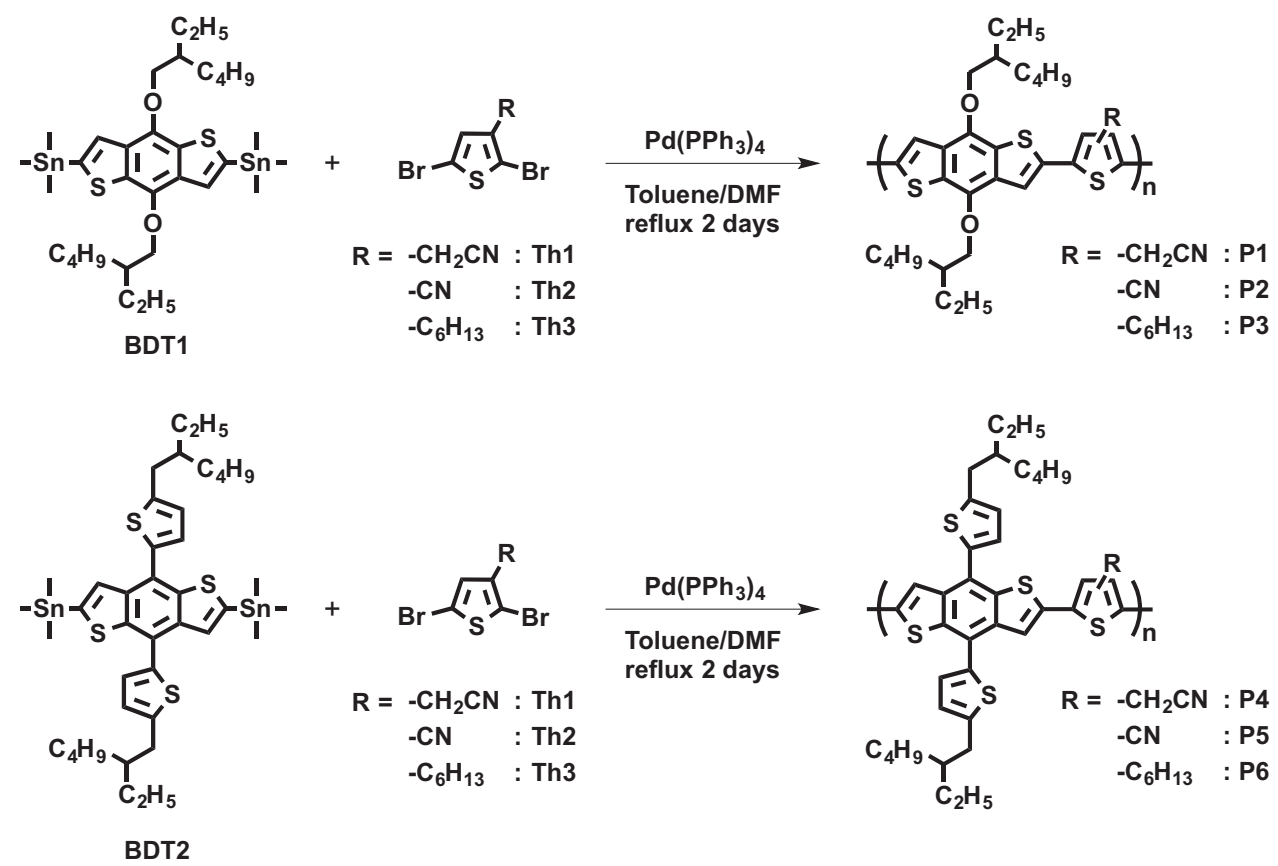

Scheme 1 Synthesis of P1-6.

Table 1 Polymerization results and thermal properties of P1-6

\begin{tabular}{lrcccc}
\hline Sample & $M_{\mathrm{n}}^{\mathrm{a}, \mathrm{b}}$ & $M_{\mathrm{w}} / M_{\mathrm{n}}^{\mathrm{a}, \mathrm{b}}$ & Yield $(\%)^{\mathrm{a}}$ & $T_{5 \mathrm{~d}}\left({ }^{\circ} \mathrm{C}\right)^{\mathrm{c}}$ & $T_{\mathrm{g}}\left({ }^{\circ} \mathrm{C}\right)^{\mathrm{c}}$ \\
\hline P1 & 11800 & 1.47 & 91 & 315 & 116 \\
P2 & 12400 & 1.23 & 78 & 317 & 110 \\
P3 & 10700 & 1.81 & 89 & 320 & 117 \\
P4 & 7500 & 1.40 & 55 & 376 & - \\
P5 & 3200 & 1.21 & 20 & 428 & - \\
P6 & 6900 & 1.70 & 79 & 430 & - \\
\hline
\end{tabular}

Values of chloroform-soluble fractions.

DDetermined by SEC using polystyrene standards in chloroform.

cMeasured under nitrogen atmosphere.

Previously reported thienyl-substituted BDT-based polymers also exhibited relatively low yields (58-29\%). ${ }^{21}$ Therefore, this problem may be due to the low solubility of the high-molecular-weight products (that is, CF-insoluble fractions). The structures of P1-6 were characterized by ${ }^{1} \mathrm{H}$ NMR spectroscopy. As shown in Figure 1, all of the peaks were assigned in the ${ }^{1} \mathrm{H}$ NMR spectrum of $\mathbf{P 1}$ (see the ${ }^{1} \mathrm{H}$ NMR spectra of P2-6 in Supplementary information).

The solubility of P1-6 in common organic solvents was evaluated, and the results are summarized in Table 2. P1 and P3 exhibited good solubility in $\mathrm{CF}$ and $o$-dichlorobenzene (DCB), whereas the solubility of $\mathbf{P 2}$ in $\mathrm{CB}$ and $\mathrm{DCB}$ was lower than that of $\mathbf{P 1}$ and $\mathbf{P} 3$ due to the short cyano side chain. For P4-6, P4 and P5 exhibited much lower solubility than P1-3, which may be due to the planar thienyl side chain and other short side chains (that is, cyano or cyanomethyl groups).

\section{Thermal properties}

The thermal properties of P1-6 were investigated by thermogravimetry and DCS measurements. The results are summarized in Table 1. As shown in Figure 2, the $5 \%$ weight decomposition temperatures $\left(T_{5 \mathrm{~d}}\right)$

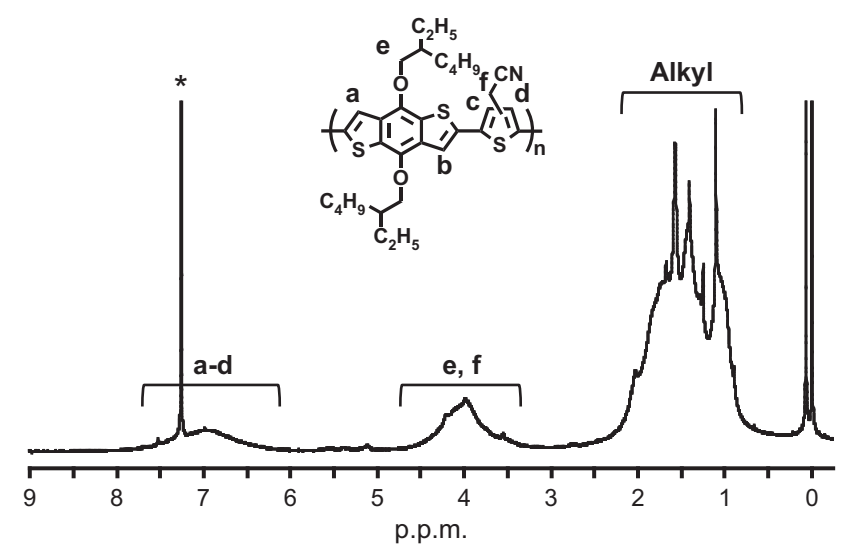

Figure $1^{1} \mathrm{H}$ NMR spectrum of $\mathbf{P 1}$ in $\mathrm{CDCl}_{3}$. The residual $\mathrm{CHCl}_{3}$ peak is marked.

were $>300^{\circ} \mathrm{C}$ in P1-6. In particular, P4-6 exhibited much higher thermal stability $\left(T_{5 \mathrm{~d}}>370^{\circ} \mathrm{C}\right)$ than $\mathbf{P 1}-\mathbf{3}\left(T_{5 \mathrm{~d}} \approx 320^{\circ} \mathrm{C}\right)$, due to the thermal stability of the thienyl side chains. In the DSC profiles (Figure 3), the glass transition temperatures $\left(T_{\mathrm{g}}\right)$ of $\mathbf{P 1} \mathbf{- 3}$ were observed in the range of 110 to $117^{\circ} \mathrm{C}$. However, the $T_{\mathrm{g}}$ of P4-6 could not be observed.

\section{Optical properties}

The optical absorption spectra of P1-6 in a dilute CF solution and as thin films were investigated (Figure 4), and the results are summarized in Table 3. In the CF solutions (Figure 4a), the maximum absorption of P1 and P2 was observed at $496 \mathrm{~nm}$ and $520 \mathrm{~nm}$, respectively, which were red-shifted compared with P3 $(473 \mathrm{~nm})$ due to the bathochromic effect of the electron-withdrawing side chains. The optical band gaps $\left(E_{\mathrm{g}}{ }^{\text {opt }}\right)$ of the P1-3 solutions were estimated to be $2.03 \mathrm{eV}, 1.88 \mathrm{eV}$ and $2.21 \mathrm{eV}$, respectively, from the onset absorption $\left(\lambda_{\text {onset }}\right)$ at $640 \mathrm{~nm}$, 
Table 2 Solubility of P1-6

\begin{tabular}{lccccc}
\hline Sample & THF & $D C M$ & $C F$ & $C B$ & $D C B$ \\
\hline P1 & \pm & - & ++ & + & ++ \\
P2 & - & - & ++ & \pm & \pm \\
P3 & \pm & + & + & + & + \\
P4 & - & - & + & - & \pm \\
P5 & - & - & \pm & - & \pm \\
P6 & \pm & \pm & ++ & \pm & + \\
\hline
\end{tabular}

Abbreviations: $\mathrm{CB}$, chlorobenzene; $\mathrm{CF}$, chloroform; DCB, o-dichlorobenzene; $\mathrm{rt}$, room temperature.

++ , soluble at $r$; + , soluble on heating; \pm , partially soluble on heating; - , insoluble.

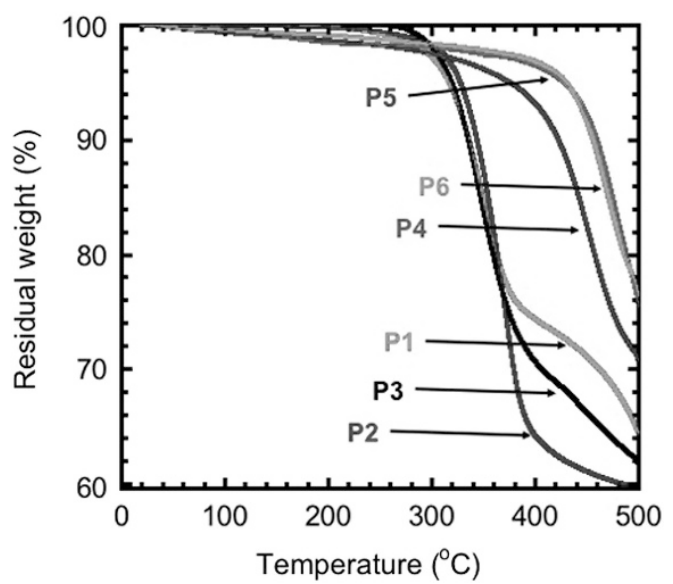

Figure 2 TG analysis of P1-6. TG, thermogravimetry. A full color version of this figure is available at Polymer Journal online.

$660 \mathrm{~nm}$ and $560 \mathrm{~nm}$, respectively. For thin films, P1-3 exhibited narrower $E_{\mathrm{g}}{ }^{\text {opt }}$ than that in solution, and $E_{\mathrm{g}}{ }^{\text {opt }}$ was estimated to be $1.65 \mathrm{eV}, 1.51 \mathrm{eV}$ and $1.76 \mathrm{eV}$, respectively (Figure 4b). P4-6 exhibited the same absorption behaviors as P1-3, and the bathochromic effects in P4 and P5 led to a red-shifted maximum absorption (498 $\mathrm{nm}$ and $529 \mathrm{~nm}$, respectively) compared with $\mathbf{P 6}(487 \mathrm{~nm})$. In addition, the absorption due to the thienyl side chain was observed in the range of 350 to $400 \mathrm{~nm}$ in P4-6, suggesting that the polymer side chains are an important factor for achieving light-harvesting properties over a wide range. The $E_{\mathrm{g}}$ opt of the P4-6 solutions was estimated to be $2.00 \mathrm{eV}$, $1.85 \mathrm{eV}$ and $2.14 \mathrm{eV}$, respectively, which were narrower in the thin films (1.61 eV, $1.49 \mathrm{eV}$ and $1.75 \mathrm{eV}$, respectively). Among P1-6, the P5 thin film exhibited the narrowest $E_{\mathrm{g}}^{\mathrm{opt}}$, and the enhanced planarity due to the thienyl and short cyano side chains contributed to the narrowing of the optical band gap.

\section{Electrochemical properties}

The electronic states of the polymer thin films were investigated by cyclic voltammetry) measurements. To determine the HOMO levels, each measurement was calibrated using the saturated calomel electrode. The electrochemical data are summarized in Figure 5. The HOMO levels of P1-3 were estimated to be $-5.53 \mathrm{eV},-5.61 \mathrm{eV}$ and $-5.28 \mathrm{eV}$, respectively, based on their onset oxidation potentials ( $E_{\mathrm{Ox}}{ }^{\text {onset }}$ ) of $1.13 \mathrm{eV}, 1.21 \mathrm{eV}$ and $0.88 \mathrm{eV}$, respectively. As expected, the incorporation of electron-withdrawing side chains led to deep HOMO levels in P1 and P2 compared with P3. P4-6 exhibited the same electrochemical behaviors as P1-3. Deep HOMO levels were observed in P4 and P5 and were estimated to be $-5.55 \mathrm{eV}$ and

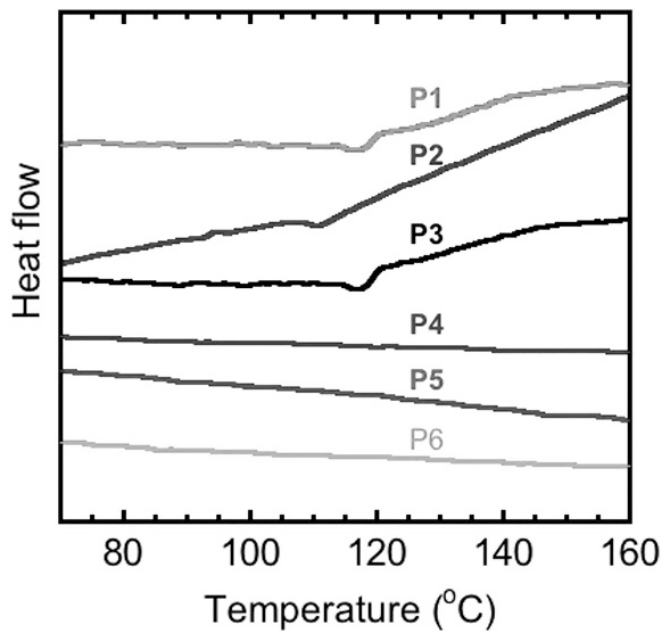

Figure 3 DSC profiles of P1-6. DSC, differential scanning calorimetry. A full color version of this figure is available at Polymer Journal online.
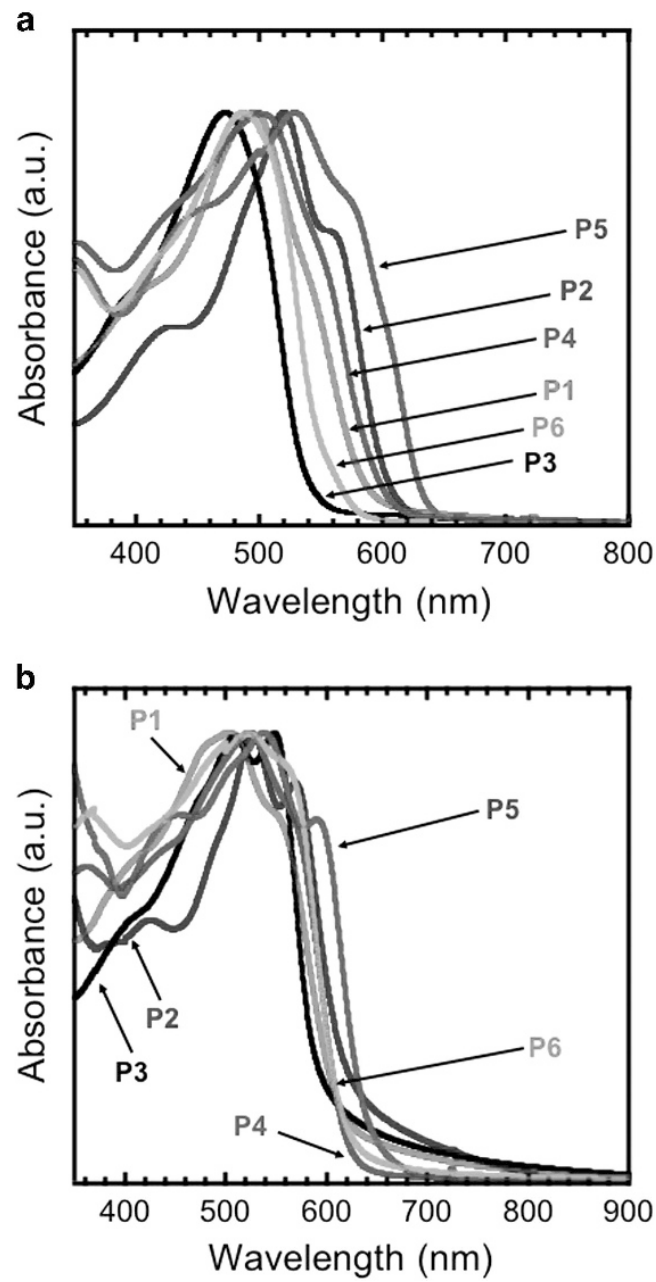

Figure 4 UV-Vis absorption of P1-6 in chloroform solutions (a) and thin films (b). UV-Vis, ultraviolet-visible. A full color version of this figure is available at Polymer Journal online. 
Table 3 Optical properties of P1-6

\begin{tabular}{|c|c|c|c|c|c|c|}
\hline \multirow[b]{2}{*}{ Sample } & \multicolumn{3}{|c|}{ Solution } & \multicolumn{3}{|c|}{ Film } \\
\hline & $\lambda_{\max }(n m)$ & $\lambda_{\text {onset }}(\mathrm{nm})$ & $\mathrm{E}_{g}{ }^{o p t}(\mathrm{eV})^{\mathrm{a}}$ & $\lambda_{\max }(n m)$ & $\lambda_{\text {onset }}(n m)$ & $\mathrm{E}_{g}{ }^{o p t}(\mathrm{eV})^{\mathrm{a}}$ \\
\hline P1 & 496 & 640 & 2.03 & 500 & 750 & 1.65 \\
\hline P2 & 520 & 660 & 1.88 & 527 & 820 & 1.51 \\
\hline P3 & 473 & 560 & 2.21 & 548 & 704 & 1.76 \\
\hline P4 & 498 & 620 & 2.00 & 529 & 770 & 1.61 \\
\hline P5 & 529 & 670 & 1.85 & 540 & 830 & 1.49 \\
\hline P6 & 487 & 580 & 2.14 & 522 & 710 & 1.75 \\
\hline
\end{tabular}

${ }^{\mathrm{a}} E_{\mathrm{g}}{ }^{\text {opt }}=1240 \lambda_{\text {onset }}(\mathrm{eV})$.

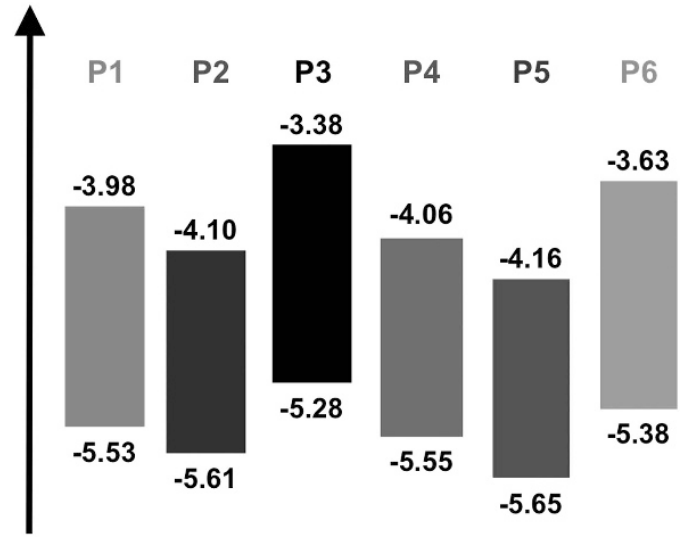

Figure $5 \mathrm{HOMO/LUMO} \mathrm{diagram} \mathrm{of} \mathrm{P1-6} \mathrm{thin} \mathrm{films.} \mathrm{A} \mathrm{full} \mathrm{color} \mathrm{version} \mathrm{of}$ this figure is available at Polymer Journal online.

$-5.65 \mathrm{eV}$, respectively. In a previous study, Prasad and co-workers ${ }^{30}$ also reported that polymers with electron-withdrawing carboxylate side chains possessed deep HOMO levels between -5.41 and $-5.50 \mathrm{eV}$. These results demonstrated that the incorporation of electron-withdrawing side chains effectively resulted in deep HOMO levels, and the electrochemical properties of our polymers were independent of the differences in the side chains in the BDT units based on the cyclic voltammetry results.

\section{Photovoltaic performance}

The photovoltaic properties of $\mathbf{P} \mathbf{1}-\mathbf{3}$ were studied using $\mathrm{PC}_{61} \mathrm{BM}$ as an acceptor material in a conventional device configuration (that is, ITO/ PEDOT:PSS/polymer:PC $\left.{ }_{61} \mathrm{BM} / \mathrm{Ca} / \mathrm{Al}\right)$. It is important to note that the photovoltaic properties of $\mathbf{P 4}$ and $\mathbf{P 5}$ were not investigated because it was difficult to fabricate OPVs because of their low solubility and low molecular weights. The current $J-V$ curves of the fabricated photovoltaics under AM1.5G solar irradiation $\left(100 \mathrm{~mW} \mathrm{~cm}^{-2}\right)$ are shown in Figure 6. The $V_{\mathrm{OC}} J_{\mathrm{SC}}$, fill factor (FF) and PCE values are summarized in Table 4 . In the $\mathrm{P} 1 / \mathrm{PC}_{61} \mathrm{BM}$ system, the OPVs with active layers fabricated from $\mathrm{CF}$ and $\mathrm{CB}$ solutions exhibited low PCEs $(<1 \%)$. By contrast, the OPV with an active layer fabricated from the DCB solution exhibited a much higher PCE $(2.34 \%)$ than that of the OPVs from the $\mathrm{CF}$ and $\mathrm{CB}$ solutions. Furthermore, the thermal annealing at $140^{\circ} \mathrm{C}$ led to the highest PCE of $2.68 \%$ with $V_{\text {oc }}$ of $0.71 \mathrm{~V}, J_{\text {sc }}$ of $10.64 \mathrm{~mA} \mathrm{~cm}^{-2}$ and FF of 0.35 . To date, the highest PCE of the OPV with the $\mathrm{P} 3 / \mathrm{PC}_{61} \mathrm{BM}$ active layer is $0.86 \%$ with $V_{\mathrm{oc}}$ of $0.59 \mathrm{~V}, J_{\mathrm{sc}}$ of $4.93 \mathrm{~mA} \mathrm{~cm}^{-2}$ and $\mathrm{FF}$ of $0.30 .{ }^{26}$ The larger $V_{\mathrm{oc}}$ of the $\mathrm{P} 1 / \mathrm{PC}_{61} \mathrm{BM}$

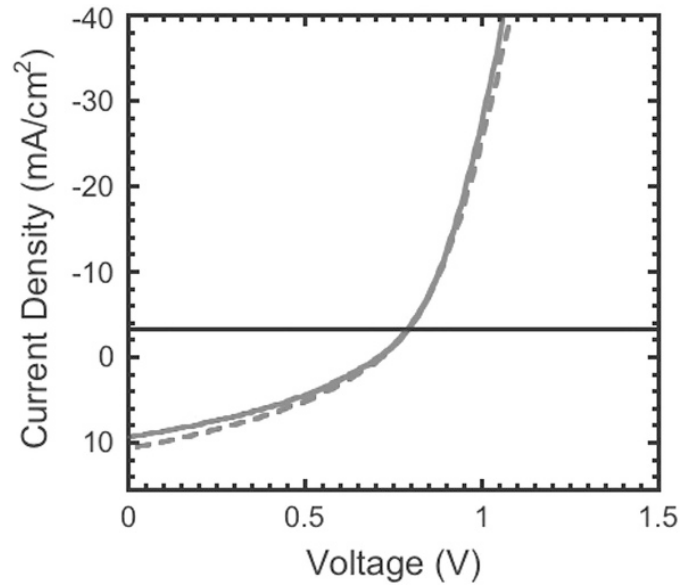

Figure $6 J-V$ characteristics of $\mathrm{P} 1 / \mathrm{PC}_{61} \mathrm{BM}$ system fabricated from the $\mathrm{DCB}$ solutions under $A M 1.5 \mathrm{G}$ irradiation $\left(100 \mathrm{~mW} \mathrm{~cm}^{-2}\right)$. The active layer was annealed at $100^{\circ} \mathrm{C}$ (solid line) and $140^{\circ} \mathrm{C}$ (dotted line). DCB, o-dichlorobenzene; PC61BM, P1/[6,6]-phenyl-C61-butyric acid methyl ester. A full color version of this figure is available at Polymer Journal online.

Table 4 OPV performance of $\mathrm{P} 1-3$ with $\mathrm{PC}_{61} \mathrm{BM}$

\begin{tabular}{|c|c|c|c|c|c|c|}
\hline Sample ${ }^{\mathrm{a}}$ & Solvent & Annealing ${ }^{\mathrm{b}}$ & $\mathrm{V}_{o c}(V)$ & $\mathrm{J}_{s c}\left(\mathrm{mAcm}^{-2}\right)$ & $F F$ & PCE (\%) \\
\hline \multirow[t]{6}{*}{ P1 } & $\mathrm{CF}$ & $100^{\circ} \mathrm{C}$ & 0.73 & 1.44 & 0.26 & 0.27 \\
\hline & & $140^{\circ} \mathrm{C}$ & 0.75 & 0.73 & 0.21 & 0.11 \\
\hline & CB & $100^{\circ} \mathrm{C}$ & 0.80 & 3.07 & 0.31 & 0.78 \\
\hline & & $140^{\circ} \mathrm{C}$ & 0.89 & 0.22 & 0.32 & 0.06 \\
\hline & DCB & $100^{\circ} \mathrm{C}$ & 0.71 & 9.34 & 0.35 & 2.34 \\
\hline & & $140^{\circ} \mathrm{C}$ & 0.71 & 10.64 & 0.35 & 2.68 \\
\hline \multirow[t]{6}{*}{ P2 } & $\mathrm{CF}$ & $100^{\circ} \mathrm{C}$ & 0.72 & 0.27 & 0.37 & 0.07 \\
\hline & & $140^{\circ} \mathrm{C}$ & 0.73 & 0.47 & 0.42 & 0.14 \\
\hline & $\mathrm{CB}$ & $100^{\circ} \mathrm{C}$ & 0.71 & 1.11 & 0.40 & 0.32 \\
\hline & & $140^{\circ} \mathrm{C}$ & 0.72 & 1.12 & 0.40 & 0.33 \\
\hline & DCB & $100^{\circ} \mathrm{C}$ & 0.68 & 2.38 & 0.38 & 0.56 \\
\hline & & $140^{\circ} \mathrm{C}$ & 0.68 & 2.72 & 0.34 & 0.63 \\
\hline $\mathrm{P}^{\mathrm{c}}$ & $\mathrm{CB}$ & $150^{\circ} \mathrm{C}$ & 0.59 & 4.93 & 0.30 & 0.86 \\
\hline
\end{tabular}

Abbreviations: CB, chlorobenzene; CF, chloroform; DCB, o-dichlorobenzene; OPV, organic photovoltaic; PCE, power conversion efficiency; PC61BM, P1/[6,6]-phenyl-C61-butyric acid methyl ester.

awith $\mathrm{PC}_{61} \mathrm{BM}$.

${ }^{\mathrm{b}}$ For 15 min under nitrogen atmosphere.

'Ref 26.

system $(0.71 \mathrm{~V})$ compared with the $\mathbf{P} 3 / \mathrm{PC}_{61} \mathrm{BM}$ system $(0.59 \mathrm{~V})$ is most likely due to the deeper HOMO level of P1 due to the incorporation of the electron-withdrawing side chains, which contributed to the higher PCEs. To improve the PCEs, 1,8-diiodooctane was introduced into the $\mathrm{P} 1 / \mathrm{PC}_{61} \mathrm{BM}$ system as an additive. ${ }^{31,32}$ The device with the $\mathrm{P} 1 / \mathrm{PC}_{61} \mathrm{BM}$ system was fabricated using the $\mathrm{DCB} / 1,8$ diiodooctane solution $(97 / 3 \mathrm{vol} \%)$ followed by thermal annealing at $140{ }^{\circ} \mathrm{C}$. Surprisingly, the PCE dramatically decreased to $1.10 \%$ with $V_{\text {oc }}$ of $0.76 \mathrm{~V}, J_{\text {sc }}$ of $4.96 \mathrm{~mA} \mathrm{~cm}^{-2}$ and FF of 0.29 (Supplementary Figure S7). This result may be due to the inferior morphology, which led to ineffective charge separation.

For the $\mathbf{P} 2 / \mathrm{PC}_{61} \mathrm{BM}$ system, low PCEs were observed for all of the devices. This unfavorable performance was due to two reasons. The first reason was the low solubility of $\mathbf{P} \mathbf{2}$ compared with $\mathbf{P} \mathbf{1}$, preventing 

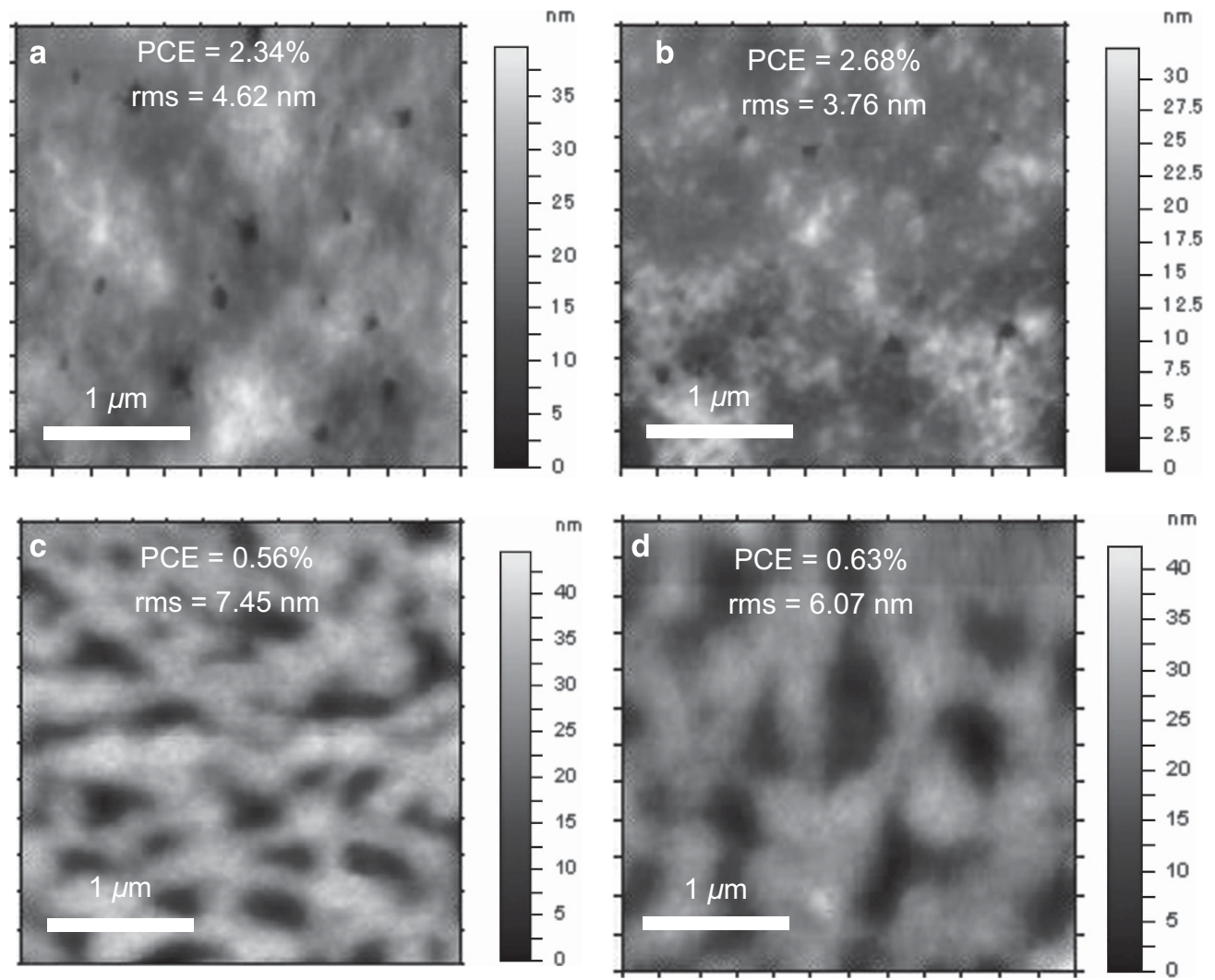

Figure 7 AFM height images of the active layers fabricated from the CDB solutions. (a) $\mathrm{P} 1 / \mathrm{PC}_{61} \mathrm{BM}$ system annealed at $100{ }^{\circ} \mathrm{C}$, (b) $\mathrm{P} 1 / \mathrm{PC}{ }_{61} \mathrm{BM}$ system annealed at $140^{\circ} \mathrm{C}$, (c) $\mathrm{P2} / \mathrm{PC}_{61} \mathrm{BM}$ system annealed at $100^{\circ} \mathrm{C}$, and (d) $\mathrm{P} 2 / \mathrm{PC}_{61} \mathrm{BM}$ system annealed at $140{ }^{\circ} \mathrm{C}$. AFM, atomic force microscopy; PC61BM, $\mathrm{P1}$ 1/6,6]-phenyl-C61-butyric acid methyl ester. A full color version of this figure is available at Polymer Journal online.

the thorough mixing of $\mathbf{P} 2$ and $\mathrm{PC}_{61} \mathrm{BM}$ in the active layer (see next section in detail). The second reason is the LUMO level of $\mathbf{P 2}$ $(-4.1 \mathrm{eV})$, which was nearly the same as that of $\mathrm{PC}_{61} \mathrm{BM}(c a .-4.1 \mathrm{eV})$ and was likely too deep for use with $\mathrm{PC}_{61} \mathrm{BM}$. However, the incorporation of electron-withdrawing side chains is an efficient method for achieving the large $V_{\text {oc }}$ and high PCE values. Tuning the depth of the HOMO/LUMO levels within the proper range by the incorporation of suitable electron-withdrawing side chains may be a promising approach for improving PCEs.

\section{Thin film morphology}

The effect of the surface morphology on the photovoltaic performance was investigated by AFM. As shown in Figure 7a, the root-mean-square roughness of the $\mathrm{P} 1 / \mathrm{PC}_{61} \mathrm{BM} \mathrm{OPV}$ with $\mathrm{PCE}=$ $2.34 \%$ was $4.62 \mathrm{~nm}$. In comparison to Figure $7 \mathrm{a}$, the device with the higher PCE (2.68\%) exhibited a smaller root-mean-square roughness (3.76 nm in Figure $7 \mathrm{~b}$ ). By contrast, the P2/PC ${ }_{61} \mathrm{BM}$ OPVs with the low PCEs (0.56 and $0.63 \%$ ) exhibited a much higher root-mean-square $(7.45 \mathrm{~nm}$ and $6.07 \mathrm{~nm}$, respectively). Furthermore, the high root-mean-square $(9.05 \mathrm{~nm})$ was also observed in the $\mathrm{P} 1 / \mathrm{PC}_{61} \mathrm{BM}$ OPVs fabricated from the $\mathrm{DCB} / 1,8$-diiodooctane solution $(\mathrm{PCE}=1.10 \%$, Supplementary Figure S8). Therefore, the OPV performance was primarily dependent on the surface roughness of the active layers. The high surface roughness of the $\mathrm{P} 2 / \mathrm{PC}_{61} \mathrm{BM}$ system may be due to the low solubility of $\mathbf{P 2}$, as previously described, which resulted in a much lower PCE than the $\mathrm{P} 1 / \mathrm{PC}_{61} \mathrm{BM}$ system.

\section{CONCLUSION}

A series of novel BDT-based low band-gap polymers P1-6 were successfully synthesized using the Stille coupling reaction. P1, 2, 4 and 5 exhibited wide light absorption due to the bathochromic effect resulting from the incorporation of electron-withdrawing side chains (that is, cyano or cyanomethyl groups) compared with $\mathbf{P 3}$ and $\mathbf{P 6}$ with hexyl side chains. The P5 thin film exhibited the narrowest optical band gap of $1.49 \mathrm{eV}$. The cyclic voltammetry measurements demonstrated that the incorporation of electron-withdrawing side chains led to deep HOMO levels, and these levels were estimated to be $-5.53 \mathrm{eV}$, $-5.61 \mathrm{eV},-5.55 \mathrm{eV}$ and $-5.65 \mathrm{eV}$ in P1, 2, 4 and 5, respectively. The OPV with the $\mathrm{P} 1 / \mathrm{PC}_{61} \mathrm{BM}$ system achieved a PCE of $2.68 \%$ with $V_{\text {oc }}$ of $0.71 \mathrm{~V}, J_{\mathrm{sc}}$ of $10.64 \mathrm{~mA} \mathrm{~cm}^{-2}$ and $\mathrm{FF}$ of 0.35 . By contrast, the OPV with the $\mathrm{P} 3 / \mathrm{PC}_{61} \mathrm{BM}$ system exhibited a PCE of $0.86 \%$ with $V_{\mathrm{oc}}$ of $0.59 \mathrm{~V}, J_{\mathrm{sc}}$ of $4.93 \mathrm{~mA} \mathrm{~cm}^{-2}$ and $\mathrm{FF}$ of 0.30 . These results demonstrate that improvement in the PCEs was accomplished by the increased $V_{\text {oc }}$ due to the deeper HOMO levels. Therefore, the incorporation of electron-withdrawing side chains is a promising strategy for improving PCEs.

1 Gunes, S., Neugebauer, H. \& Sariciftci, N. S. Conjugated polymer-based organic solar cells. Chem. Rev 107, 1324-1338 (2007).

2 Thompson, B. C. \& Fréchet, J. M. Polymer-fullerene composite solar cells. Angew. Chem. Int. Ed. 47, 58-77 (2007).

3 Dennler, G., Scharber, M. C. \& Brabec, C. J. Polymer-fullerene bulk-heterojunction solar cells. Adv. Mater. 21, 323-1338 (2009). 
4 Zhou, H., Yang, L. \& You, W. Rational design of high performance conjugated polymers for organic solar cells. Macromolecules 45, 607-632 (2012).

5 Liang, Y., Xu, Z., Xia, J., Tsai, S.-T., Wu, Y., Li, G., Ray, C. \& Yu, L. For the bright future-bilk heterojunction polymer solar cells with power conversion efficiency of $7.4 \%$. Adv. Mater. 22, E135-E138 (2010).

6 Chen, H.-Y., Hou, J., Zhang, S., Liang, Y., Yang, G., Yang, Y., Yu, L., Wu, Y. \& Li, G. Polymer solar cells with enhanced open-circuit voltage and efficiency. Nat. Photonics $\mathbf{3}$, 649-653 (2009).

7 Son, H. J., Wang, W., Xu, T., Liang, Y., Wu, Y. \& Yu, L. Synthesis of fluorinated polythiophene-co-benzodithiophenes and effect of fluorination on the photovoltaic properties. J. Am. Chem. Soc. 133, 1885-1894 (2011).

8 Zhang, Y., Hau, S. K., Yip, H.-L., Sun, Y., Acton, O. \& Jen., A. K.-Y. Efficient polymer solar cells based on the copolymers of benzodithiophene and thienopyrroledione. Chem. Mater. 22, 2696-2698 (2010).

9 Zhang, M., Gu, Y., Guo, X., Liu, F., Zhang, S., Huo, L., Russell, T. P. \& Hou, J. Efficient polymer solar cells based on benzodithiazole and alkylphenyl substituted benzodithiophene with a power conversion efficiency over 8\%. Adv. Mater. 25, 4944-4949 (2013).

10 Ma, Z., Wang, E., Jarvid, M. E., Henriksson, P., Inganäs, O., Zhang, F. \& Andersson, M. R. Synthesis and characterization of benzodithiophene-isoindigo polymers for solar cells. J. Mater. Chem. 22, 2306-2314 (2012).

$11 \mathrm{He}$, Z., Zhong, C., Su, S., Xu, M., Wu, H. \& Cao, Y. Enhanced power-conversion efficiency in polymer solar cells using an inverted device structure. Nat. Photonics 6 , 591-595 (2012).

12 Mühlbacher, D., Scharber, M., Morana, M., Zhu, Z., Waller, D., Gaudiana, R. \& Brabec, C. High photovoltaic performance of a low-bandgap polymer. Adv. Mater. 18, 2884-2889 (2006).

13 Peet, J., Kim, J. Y., Coates, N. E., Ma, W. L., Moses, D., Heeger, A. J. \& Bazan, G. C. Efficiency enhancement in low bandgap polymer solar cells by processing with alkane dithiols. Nat. Mater. 6, 497-500 (2007).

14 Hou, J., Chen, H.-Y., Zhang, S., Li, G. \& Yang, Y. synthesis, characterization, and photovoltaic properties of a low band gap polymer based on silole-containing polythiophene and 2, 1, 3-benzothiazole. J. Am. Chem. Soc. 130, 16144-16145 (2008).

15 Wienk, M. M., Turbiez, M., Gilot, J. \& Janssen, R. A. J. Narrow-bandgap diketo-pyrrolo polymer solar cells: effect of processing on the performance. Adv. Mater. 20, 2556-2560 (2008).

16 Zou, Y., Najari, A., Berrouard, P., Beaupré, S., Aïch, B. R., Tao, Y. \& Leclerc, M. A thieno[3,4-c]pyrrole-4,6-dione-based copolymer for efficient solar cells. J. Am. Chem. Soc. 132, 5330-5331 (2010).

17 Zhan, X., Facchetti, A., Barlow, S., Marks, T. J., Ratner, M. A., Wasielewski, M. R. \& Marder, S. R. Rylene and ralated diimides for organic electronics. Adv. Mater. 23, 268-284 (2011).

18 Nakabayashi, K. \& Mori, H. All-polymer solar cells based on fully conjugated block copolymers composed of poly(3-hexylthiophene) and poly(naphthalene bisimide) segments. Macromolecules 45, 9618-9625 (2012).
19 Nakabayashi, K. \& Mori, H. Palladium-catalyzed direct arylation approach to synthesize naphthalene bisimide-based low-band-gap polymers. Chem. Lett. 42, 717-718 (2013).

20 Khlyabich, P. P., Rudenko, A. E. \& Thompson, B. C. Random poly(3-hexylthiophene-cocyanothiophene) copolymers with high open-circuit voltage in organic solar cells. $J$. Polym. Sci. A Polym. Chem. 52, 1055-1058 (2014).

21 He, Y., Zhou, Y., Zhao, G., Min, J., Guo, X., Zhang, B., Zhang, M., Zhang, J., Li, Y., Zhang, F. \& Inganäs, O. Poly(4,8-bis(2-ethylhexyloxy)benzo[1,2-b:4,5-b']dithiophene vinylene): synthesis, optical and photovoltaic properties. J. Polym. Sci. A Polym. Chem 48, 1822-1829 (2010).

22 Liang, Y., Feng, D., Wu, Y., Tsai, S.-T., Li, G., Ray, C. \& Yu, L. Highly efficient solar cell polymers developed via fine-tuning of structural and electronic properties. J. Am. Chem. Soc. 131, 7792-7799 (2009).

23 Chung, H.-S., Lee, W.-H., Song, C. E., Shin, Y., Kim, J., Lee, S. Y., Shin, W. S., Moon, S.-J. \& Kang, I.-N. Highly conjugated side-chain-substituted benzo[1,2-b:4,5-b] dithiophene-based conjugated polymers for use in polymer solar cells. Macromolecules 47, 97-105 (2014).

24 Huo, L., Zhang, S., Guo, X., Xu, F., Li, Y. \& Hou, J. Replacing alkoxy groups with alkylthienyl groups: a feasible approach to omprove the properties of photovoltaic polymers. Angew. Chem. Int. Ed. 50, 9697-9702 (2011).

25 Hsu, S.-L., Chen, C.-M., Cheng, Y.-H. \& Wei, K. H. New carbazole-based conjugated polymers containing pyridylvinyl thiophene units for polymer solar cell applications; morphological stabilization through hydrogen bonding. J. Polym. Sci. A Polym. Chem. 49, 603-611 (2011).

26 Tan, L., Curtis, M. D. \& Francis, A. H. Charge transfer in ferrocene-bearing poly (thiophene)s and application in organic bilayer photocells. Macromolecules 35, 4628-435 (2002).

27 Harada, K. Kokai Tokkyo Koho. Japanese patent 2010-057917 (2010).

28 Paoprasert, P., Spalenka, J. W., Peterson, D. L., Ruther, R. E., Hamers, R. J., Evans, P. G. \& Gopalan, P. Grafting of poly(3-hexylthiophene) brushes on oxides using click chemistry. J. Mater. Chem. 20, 2651-2658 (2010).

29 Nie, Y., Zhao, B., Tang, P., Jiang, P., Tian, Z., Shen, P. \& Tan, S. Synthesis and photovoltaic properties of copolymers based on benzo[1,2-b:4,5- $b$ ] dithiophene and thiophene with electron-withdrawing side chains. J. Polym. Sci. A Polym. Chem. 49, 3604-3614 (2011).

30 Cho, M. J., Seo, J., Luo, K., Kim, K. H., Choi, D. H. \& Prasad, P. N. Polymer solar cells fabricated with 4,8-bis(2-ethylhexyloxy)benzo[1,2-b:4,5- $b^{\prime}$ 'd dithiophene and alkylsubstituted thiophene-3-carboxylate-containing conjugated polymers: Effect of alkyl side-chain in thiophene-3-carboxylate monomer on the device performance. Polymer 53, 3835-3841 (2012).

31 Lee, J. K., Ma, W. L., Brabec, C. J., Yuen, J., Moon, J. S., Kim, Y., Lee, K., Bazan, G. C. \& Heeger, A. J. Processing additives for improved efficiency from bulk heterojunction solar cells. J. Am. Chem. Soc. 130, 3618-3623 (2008).

32 Sun, Y., Welch, G. C., Leong, W. L., Takacs, C. J., Bazan, G. C. \& Heeger, A. J. Solution-processed small-molecule solar cells with $6.7 \%$ efficiency. Nat. Mater. 11 , 44-48 (2012).

Supplementary Information accompanies the paper on Polymer Journal website (http://www.nature.com/pj) 